\author{
Ivan Taritaš \\ Mario Sremec \\ Darko Kozarac \\ Mislav Blažić \\ Zoran Lulić
}

DOI: $10.21278 /$ TOF.41101

ISSN 1333-1124

eISSN 1849-1391

\title{
THE EFFECT OF OPERATING PARAMETERS ON DUAL FUEL ENGINE PERFORMANCE AND EMISSIONS - AN OVERVIEW
}

\begin{abstract}
Summary
In order to decrease harmful exhaust gas emissions from internal combustion engines, researchers are continuously looking for alternative fuels and combustion techniques, and in this context the use of natural gas as a supplement for conventional fuels has been suggested. Since natural gas has high autoignition temperature, it cannot be used in compression ignition engines as the in-cylinder temperature around the top dead center is simply not high enough to ignite it. Therefore, in such an application natural gas has to be used with high reactivity fuel, usually diesel fuel. In these applications diesel fuel is used solely as a high energy ignition device, while natural gas is used as primary fuel. This type of combustion process is called dual fuel combustion process. This paper presents the effect of operating parameters, such as diesel fuel injection pressure, injection timing, diesel fuel mass, diesel fuel substitution ratio and intake charge conditioning, as well as engine load and speed on efficiency and harmful exhaust gas emissions from dual fuel diesel/natural gas internal combustion engines.
\end{abstract}

Key words: $\quad$ dual fuel engine, combustion, performance, emissions

\section{Introduction}

As a result of the growth of world population and industry, energy consumption and the burning of fossil fuels are steadily rising [1]. Burning of fossil fuels has been recognized as the major contributor to the increase in greenhouse gas (GHG) emissions [2]. Moreover, as the transport sector is recognized as the second major pollutant, the governments around the world have imposed a number of regulations to reduce its harmful effect on the environment. In this context, hybrid electric vehicle technology has proven to be a viable solution in the light duty vehicle application [3], while the use of compressed natural gas (CNG) as fuel in the heavy-duty vehicle application has seen a large growth in the last couple of years [4]. Even though CNG is also a fossil fuel, its use as an energy source in IC engines has been promoted due to its worldwide availability and cleaner nature of combustion, which offers an opportunity to reduce GHG emissions [1].

Since CNG primarily consists of methane (87 to $97 \%$ mole based), which has the highest hydrogen to carbon $(\mathrm{H} / \mathrm{C})$ ratio out of all hydrocarbon fuels, it offers a theoretical 
potential to reduce the $\mathrm{CO}_{2}$ emission from IC engines by nearly $25 \%$, compared to conventional liquid fuels [1]. If one compares the properties of methane to the properties of conventional liquid fuels (gasoline or diesel), methane has higher octane rating, higher lower heating value per unit mass, higher stoichiometric air to fuel ratio, significantly lower molar mass and lower laminar flame speed at the in-cylinder conditions [6]. Due to its higher octane rating it is less prone to auto-ignition. Although it has a higher lower heating value, as a result of the higher stoichiometric air to fuel ratio the heating value of the mixture is similar to conventional liquid fuels. On the other hand, CNG has significantly lower density, which means that a significantly larger container is required to store the same amount of energy.

CNG has been used in IC engines since the beginning of the $20^{\text {th }}$ century, while the first commercial CNG powered vehicle was produced in 1939 [1]. CNG can be used in both sparkignition (SI) and compression-ignition (CI) engines.

\subsection{CNG in spark-ignition (SI) engines}

In spark-ignition (SI) engines, a complete substitution of conventional liquid fuel with CNG can be achieved. Due to CNG's better mixing properties, if an engine is appropriately modified and adjusted, combustion efficiency increases and hydrocarbon (HC) and carbon monoxide (CO) emissions decrease. As a result of the higher autoignition temperature, the use of CNG in SI engines enables operation at higher compression ratio without any danger of running into engine knock and thus damaging the engine vital parts. On the one hand, the operation at the higher compression ratio leads to improved thermal efficiency, while on the other hand it leads to the in-cylinder temperature increase which results in excessive $\mathrm{NO}_{\mathrm{X}}$ emissions. The usual practice in dealing with $\mathrm{NO}_{\mathrm{X}}$ emissions is the use of a 3-way catalyst, but in this case the mixture has to be stoichiometric. SI-CNG engines with stoichiometric mixture generally exhibit lower efficiency compared to CI engines, and in order to increase their efficiency SI-CNG engines are operated with lean mixtures. In such an operation $\mathrm{NO}_{\mathrm{X}}$ emissions are high and in order to reduce emissions the engine is run with a very lean mixture [7], which in combination with lower laminar flame speed of CNG increases the combustion duration and can lead to misfires, and significantly reduce the efficiency [7]. To avoid this, spark timing needs to be optimized (advanced). As CNG has significantly lower molar mass, for the same mass it displaces more air in the cylinder which means that the engine volumetric efficiency decreases, which ultimately leads to a decrease in the engine output power. All the above mentioned effects prevent the SI-CNG engines to obtain CI engine-like efficiencies with low exhaust gas emissions.

\section{2 $\mathrm{CNG}$ in compression-ignition (CI) engines}

Compared to the SI engine, the compression-ignition (CI) engine has a significantly higher compression ratio which leads to improved thermal efficiency. Since CNG has high autoignition temperature, when used in conventional CI engines it will not ignite [5], and therefore in these engines it is utilized in the so-called dual fuel combustion process [6]. In the dual fuel combustion process, CNG, which is the main energy source, is ignited by an appropriate amount of highly reactive fuel, usually diesel fuel [5]. The relative amount of $\mathrm{CNG}$ in the combustion process is usually defined as diesel substitution ratio. Diesel substitution ratio is the ratio of energy supplied by CNG to the total amount of energy supplied by diesel fuel and CNG. There are three main types of dual fuel combustion that lead to three different engine concepts. The first is the high pressure direct injection (HPDI) dual fuel engine which allows direct injection of both fuels into the cylinder. However, such a strategy requires a completely new engine design and it is not applicable for the conversion of existing Diesel engines to dual fuel operation. In the second approach, the usually called 
conventional dual fuel engine, $\mathrm{CNG}$ is injected into the intake manifold, while diesel fuel is injected directly into the cylinder through the existing injector. The main benefit of such an application is easy conversion from conventional Diesel to dual fuel operation without significant changes to the overall engine design. Also, in the case when one runs out of CNG, such an engine can be run solely on diesel fuel, which is not possible in the case of HPDI due to the specific injector design [8]. Although HPDI offers Diesel-like indicated thermal efficiency at all loads and engine speeds with approximately $95 \%$ of the energy coming from CNG [9], the application of the conventional dual fuel operation is interesting because it enables easy engine conversion and the potential to run engine solely on diesel fuel when needed. In the third approach, both fuels are port injected and premixed; such a combustion process is called dual fuel homogeneous charge compression ignition (HCCI) [10]. In such an operation, combustion intensity and phasing are controlled by intake conditions (temperature and pressure), fuel blending and equivalence ratio. Even though the HCCI combustion process offers quite high efficiency and low $\mathrm{NO}_{\mathrm{x}}$ emissions, the control of combustion phasing is rather challenging.

The topic of this paper are conventional dual fuel diesel/CNG engines, more specifically the influence of operating parameters on dual fuel combustion as well as the influence of dual fuel combustion on engine performance. The main conclusions of the paper are derived from an extensive literature review and preliminary results of experimental and numerical studies conducted by the authors.

\section{Conventional dual fuel engine}

The conversion of a Diesel engine to a conventional dual fuel engine requires the addition of a gas supply system to the intake and the modification of the engine control unit (ECU). In this way, modern Diesel engines can be adjusted to operate in the dual fuel mode without any additional modifications to the engine structure and design. The operating principle of a conventional dual fuel engine is shown in Figure 1.

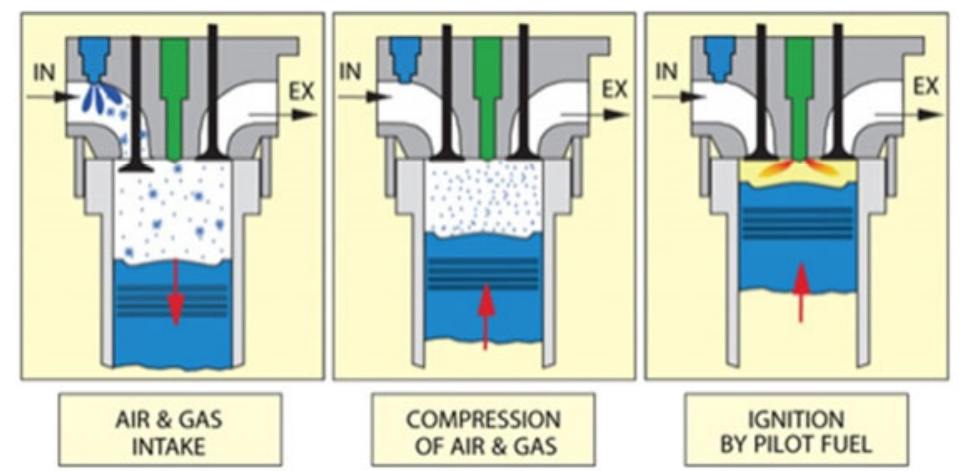

Fig. 1 Operating principle of a conventional dual fuel engine. Reproduced from [11]

$\mathrm{CNG}$ is injected into the intake manifold and mixed with air; during the intake stroke, $\mathrm{CNG}$ /air mixture is induced into the cylinder and compressed during the compression stroke. At the end of the compression stroke, $\mathrm{CNG}$ does not ignite as a result of its high autoignition temperature, and therefore a small amount of highly reactive fuel (diesel fuel) is injected into the cylinder. Diesel fuel evaporates, mixes with the surrounding charge and ignites, and thus creates multiple ignition sources for the surrounding $\mathrm{CNG}$ /air mixture. Once the appropriate temperature/pressure conditions inside the combustion chamber have been achieved, multiple flames start to propagate through the premixed CNG/air mixture. In conventional dual fuel engines, load is usually controlled by the amount of premixed CNG, while only a small amount of diesel fuel is injected to ignite the premixed mixture. The comparison between 
conventional dual fuel and Diesel engine performance has been given in several publications $[8,12,13]$, and from the literature it can be seen that in the dual fuel engine:

1. Soot emissions are considerably lower, while $\mathrm{HC}$ emissions are higher in the entire operating range.

2. $\mathrm{CO}$ emissions are generally slightly higher, while $\mathrm{NO}_{\mathrm{X}}$ emissions are generally slightly lower.

3. Efficiency is significantly lower at low load, while at higher load Diesel engine-like efficiency can be achieved.

4. Due to fuel properties, $\mathrm{CO}_{2}$ emissions are lower compared to the Diesel engine; this is more pronounced at higher load, where the dual fuel engine operates with Diesellike efficiency.

A major drawback of the conventional dual fuel operation is significantly reduced engine efficiency and increased $\mathrm{HC}$ and $\mathrm{CO}$ emissions at low load [8], which is a result of flame quenching or even misfires caused by very low flame speed through the too lean $\mathrm{CNG}$ /air mixture. On the other side, even though $\mathrm{NO}_{\mathrm{X}}$ emissions decrease, they are still quite high [8], as the flame propagation through the premixed mixtures raises the in-cylinder temperature, and consequently the $\mathrm{NO}_{\mathrm{X}}$ formation. Also, as a result of the high compression ratio, knock and preignition might occur at high loads [8]. Some researchers have noticed injector tip overheating at high diesel substitution ratios [8], which is caused by a smaller fuel flow through the fuel injector and locally high flame temperatures. Furthermore, dual fuel engines are subject to fuel slip into the exhaust port during the valve overlap period which results in an increase in $\mathrm{HC}$ emissions, largely composed of methane. This phenomenon occurs at all ranges of engine loads and speeds, especially in charged engines because of a positive pressure difference between intake and exhaust pipes [14].

Conventional dual fuel engine performance significantly depends on the engine operating parameters (injection setup and diesel fuel substitution ratio), as well as engine load and engine speed $[12,13]$. All of these effects are closely linked to the differences in the combustion process between the Diesel and the conventional dual fuel engine. In the following chapters the influence of aforementioned parameters on combustion characteristics and engine performance will be presented.

\section{Combustion process in conventional dual fuel engine}

Conventional dual fuel combustion process is a blend of a mixing-controlled combustion process (typical of CI engines) and flame propagation (typical of SI engines). In the mixing-controlled combustion process, combustion is governed by the fuel-air mixing which is controlled by global fluid motion and local mixing governed by the turbulence. Flame propagation occurs in the cases when fuel and air are premixed. It is usually triggered by an ignition source from where flame travels through the premixed mixture. Conventional dual fuel combustion can be divided into three main phases:

1. premixed (chemically controlled) combustion of the diesel fuel

2. mixing-controlled combustion of diesel fuel

3. flame propagation through the premixed $\mathrm{CNG}$ /air mixture

After diesel fuel is injected, it mixes with the $\mathrm{CNG}$ /air mixture and evaporates. After some chemically defined ignition delay time diesel/CNG/air mixture ignites. The initial combustion rate is determined by the amount of fuel in the spray region that is prepared for combustion. It was found [15] that the addition of CNG prolongs the ignition delay time of diesel fuel. This is partially a result of lower in-cylinder temperature and pressure at the end of compression stroke and predominantly it is a result of the chemical influence of CNG on 
the auto ignition process of the diesel/CNG/air mixture [16]. Lower compression temperature and pressure are a result of the decreased ratio of specific heats of the CNG/air mixture to pure air, and partially a result of the decreased volumetric efficiency compared to the conventional diesel operation which lowers the in-cylinder pressure at the intake valve closing moment. Since dual fuel combustion exhibits a prolonged ignition delay and a significantly lower diesel fuel amount, the direct injection setup (injection pressure and start of the injection moment) needs to be appropriately modified (optimized).

Once appropriate temperature/pressure conditions in the combustion chamber are achieved, flame propagation through the premixed $\mathrm{CNG}$ /air mixture is initiated at multiple locations inside the cylinder. Contrary to conventional SI engines that feature only one spark plug and thus one flame that propagates through the combustion chamber, in the case of conventional dual fuel engine, there are multiple flames that propagate through the combustion chamber, which is shown in [8]. It was concluded [8] that the number of flames that propagate through the combustion chamber coincide with the number of nozzles on the diesel fuel injector. At the same time, the unburned fuel that is present in the spray region mixes with the surrounding combustion products and burns in the mixing-controlled combustion mode. Depending on the load and on the ratio of diesel to CNG, specific phase contributes more or less to the overall burning rate which either moves the conventional dual fuel combustion process closer to that of CI engines or closer to that of SI engines.

\section{The effect of operating parameters on combustion, performance and emissions}

Conventional dual fuel engine performance (torque, power and efficiency) and exhaust gas emissions (hydrocarbon, carbon monoxide, nitrogen oxides and soot) depend on the engine operating parameters because they affect the way in which the combustion process is governed. The operating and design parameters which have a profound effect on the conventional dual fuel combustion process are:

1. diesel fuel injection pressure, injection timing and diesel fuel mass

2. diesel fuel substitution ratio

3. intake charge conditioning.

The experimental study on the influence of Diesel fuel injection parameters and engine load and speed on the dual fuel engine performance was conducted at UC Berkeley, where a 2.0 liter production type Diesel engine was adjusted to operate in a conventional dual fuel mode. The main engine characteristics are given in Table 1, while the additional information regarding the experimental setup and all investigated parameters can be found in [16].

Table 1 Engine characteristics

\begin{tabular}{|l|l|}
\hline Displacement & $1968 \mathrm{~cm}^{3}$ \\
\hline Bore & $81 \mathrm{~mm}$ \\
\hline Stroke & $95.5 \mathrm{~mm}$ \\
\hline Valves per cylinder & 4 \\
\hline Compression ratio & $16.5: 1$ \\
\hline
\end{tabular}

\subsection{Diesel fuel injection pressure, injection timing and diesel fuel mass}

As already mentioned, since a part of the diesel fuel is replaced with $\mathrm{CNG}$, a smaller amount of the diesel fuel is injected into the cylinder which means that in order to obtain optimal combustion process the injection pressure has to be modified. In the first part of this section, the influence of the injection pressure on the dual fuel engine operation is presented. 
As the injection pressure increases, velocity of the liquid fuel at the nozzle exit increases. This leads to enhanced liquid fuel atomization and charge entrainment into the spray region, as well as enhanced evaporation rate and spray penetration. Generally, as the injection pressure increases, more fuel is available for combustion at the moment of ignition, which leads to more intense premixed combustion in the spray region. This increases the temperature and promotes flame propagation through the premixed charge which leads to a higher in-cylinder pressure and a decrease in $\mathrm{HC}$ emissions. In the experiments conducted by the authors, it was shown that the initial increase in the injection pressure from 250 to 500 bar led to a decrease in peak pressure and combustion rate (Figure 2). However, a further increase in the injection pressure to 750 bar resulted in an increase in peak pressure and combustion rate. Furthermore, as a result of an increase in the in-cylinder temperature, $\mathrm{NO}_{\mathrm{X}}$ emissions increased, as can be seen in Figure 3. On the other hand, an excessive increase in the injection pressure can lead to fuel over-mixing which causes a reduction in the initial burning rate. This is a result of the leaner spray region and can lead to a decrease in combustion and indicated thermal efficiencies and an increase in $\mathrm{HC}$ emissions as the flame propagation is deteriorated. In such case, a decrease in the in-cylinder temperature leads to a decrease in $\mathrm{NO}_{\mathrm{X}}$ emissions.
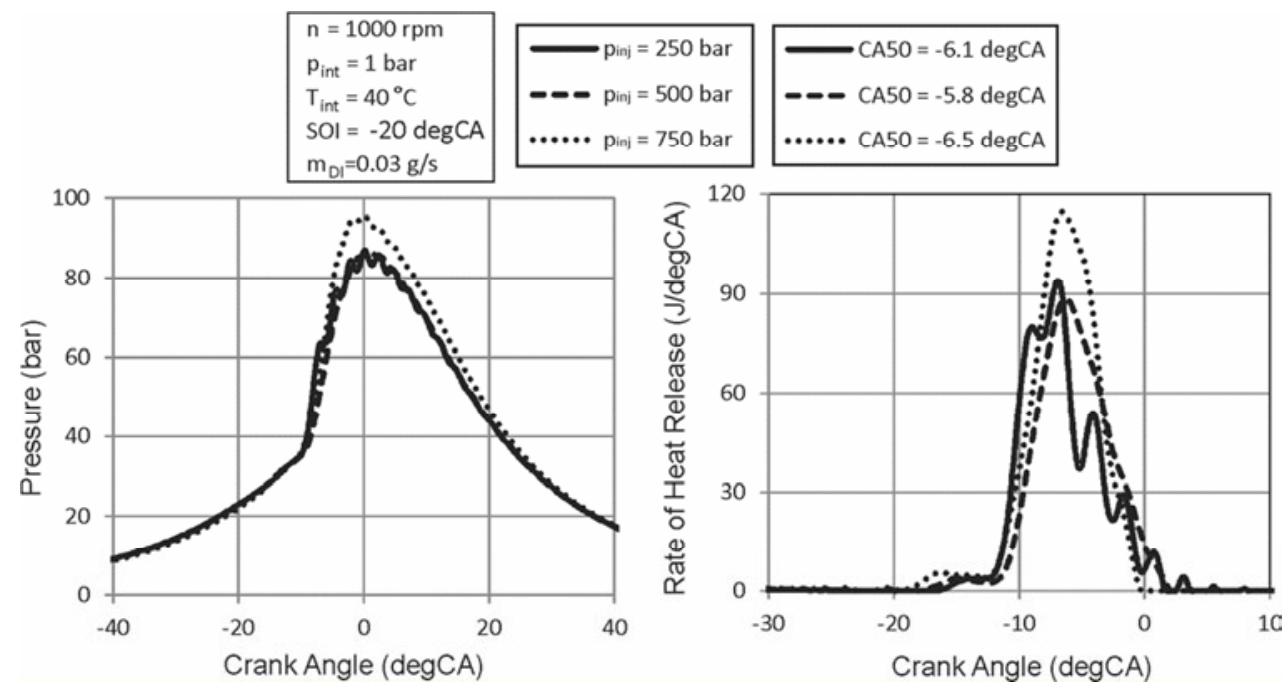

Fig. 2 In-cylinder pressure and rate of heat release at different injection pressures
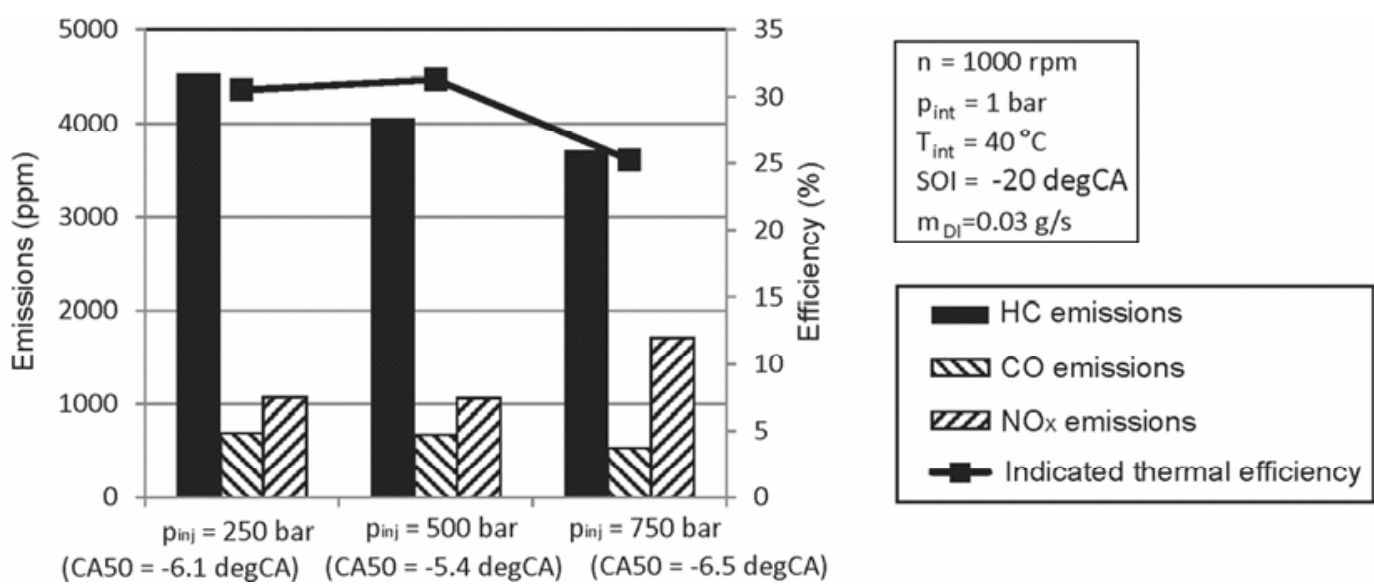

$($ CA50 $=-6.1 \operatorname{deg} C A) \quad($ CA50 $=-5.4 \operatorname{deg} C A) \quad($ CA50 $=-6.5 \operatorname{deg}$ CA $)$

Fig. $3 \mathrm{HC}, \mathrm{CO}$ and $\mathrm{NO}_{\mathrm{X}}$ emissions and indicated thermal efficiency at different injection pressures

In the experiments conducted by the authors, it was shown that even though overmixing did not occur, an increase in the injection pressure led to a decrease in the indicated thermal efficiency. The fact that over-mixing did not occur is supported by an increase in the cylinder pressure and temperature, and an increase in $\mathrm{NO}_{\mathrm{X}}$ emissions. In this case, the 
indicated thermal efficiency decreased as a result of deterioration in the combustion phasing as too early phasing led to an increase in heat transfer to the combustion chamber walls. Finally, it is important to mention that the diesel fuel injection pressure has a relatively small influence on the overall combustion process (combustion intensity and phasing) compared to other operating parameters, especially at high diesel fuel substitution ratios. This is a clear indication that in order to find an optimal injection setup, injection timing also needs to be modified.

The effect of injection timing on the dual fuel engine operation is presented in Figures 4 and 5. It has been found that the advance in the start of injection (SOI) timing leads to an increase in ignition delay as diesel is injected at a lower temperature. Although the ignition delay is prolonged as the SOI is advanced, at moderate SOI timings the start of combustion is advanced since the increase in ignition delay is relatively smaller than the change in injection timing (Figure 4: SOI $=10^{\circ}$ and $\mathrm{SOI}=20^{\circ}$ ). In this case, this leads to an increase in the intensity of the initial burning rate and hence an increase in the in-cylinder temperature, indicated thermal efficiency and $\mathrm{NO}_{\mathrm{X}}$ emissions, and a decrease in $\mathrm{HC}$ emissions (Figure 5).

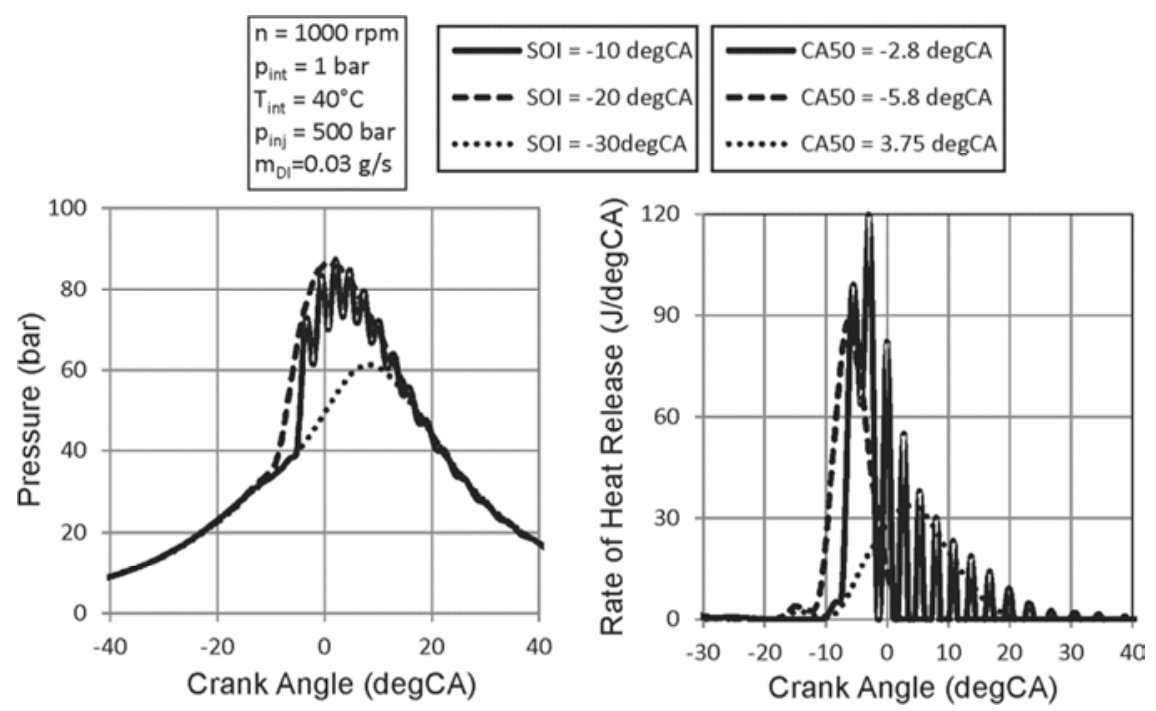

Fig. 4 In-cylinder pressure and rate of heat release for different injection timings
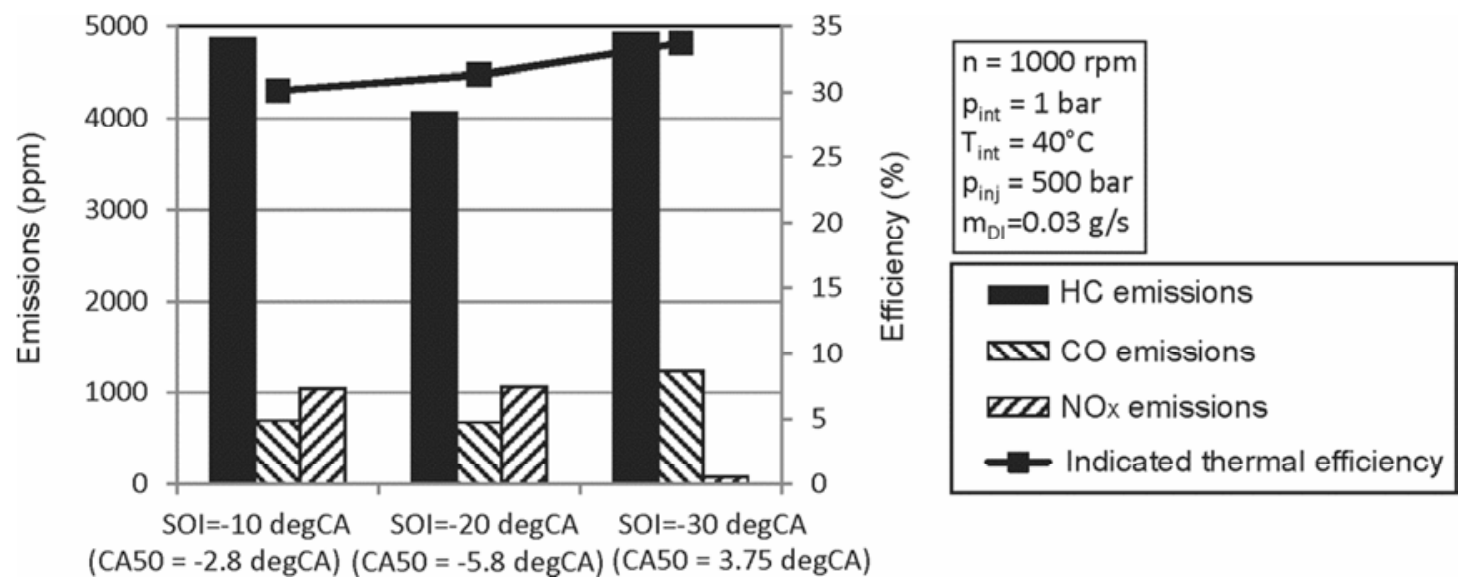

Fig. $5 \mathrm{HC}, \mathrm{CO}$ and $\mathrm{NO}_{\mathrm{X}}$ emissions and indicated thermal efficiency for different injection timings

The indicated thermal efficiency increases as a result of better flame propagation through the premixed mixture. However, as a result of an increase in temperature, knock tendency increases as well, especially at higher loads [18]. Advancing of injection timing beyond a certain point leads to over-mixing of the spray as a result of an excessive ignition 
delay. In such a case, the diesel/air mixture is significantly leaned out and since diesel shows strong sensitivity of the ignition delay to fuel richness ( $\phi$-sensitivity) [19], the ignition delay is prolonged even further. Therefore, even though in the SOI was advanced even more, the actual start of combustion was delayed and the peak rate of heat release was lowered (SOI = $30^{\circ}$ in Figure 4). This causes a decrease in temperature and $\mathrm{NO}_{\mathrm{X}}$ emissions and an increase in $\mathrm{HC}$ emissions as the flame propagation deteriorates (Figure 5). In this case, the indicated thermal efficiency does not generally have to decrease, as shown in Figure 5. In this particular case, the indicated thermal efficiency actually increased even though $\mathrm{HC}$ emissions increased. This is due to the fact that the diesel fuel mass that ignited was sufficient to promote flame propagation through the premixed mixture. Even though this flame propagation was slower and eventually quenched, the more optimal combustion phasing and the lower in-cylinder temperature led to a decrease in heat losses and increase in the indicated thermal efficiency.

The effect of the diesel fuel mass on the dual fuel engine operation is presented in Figures 6 and 7, and it has been shown that as the diesel fuel mass increases, combustion phasing is advanced (Figure 6). The advancing of combustion with the increase in the diesel fuel mass is mainly caused by strong $\phi$-sensitivity of diesel fuel, but also by the fact that more diesel fuel will create a "stronger" ignition point for flame propagation through the premixed mixture.
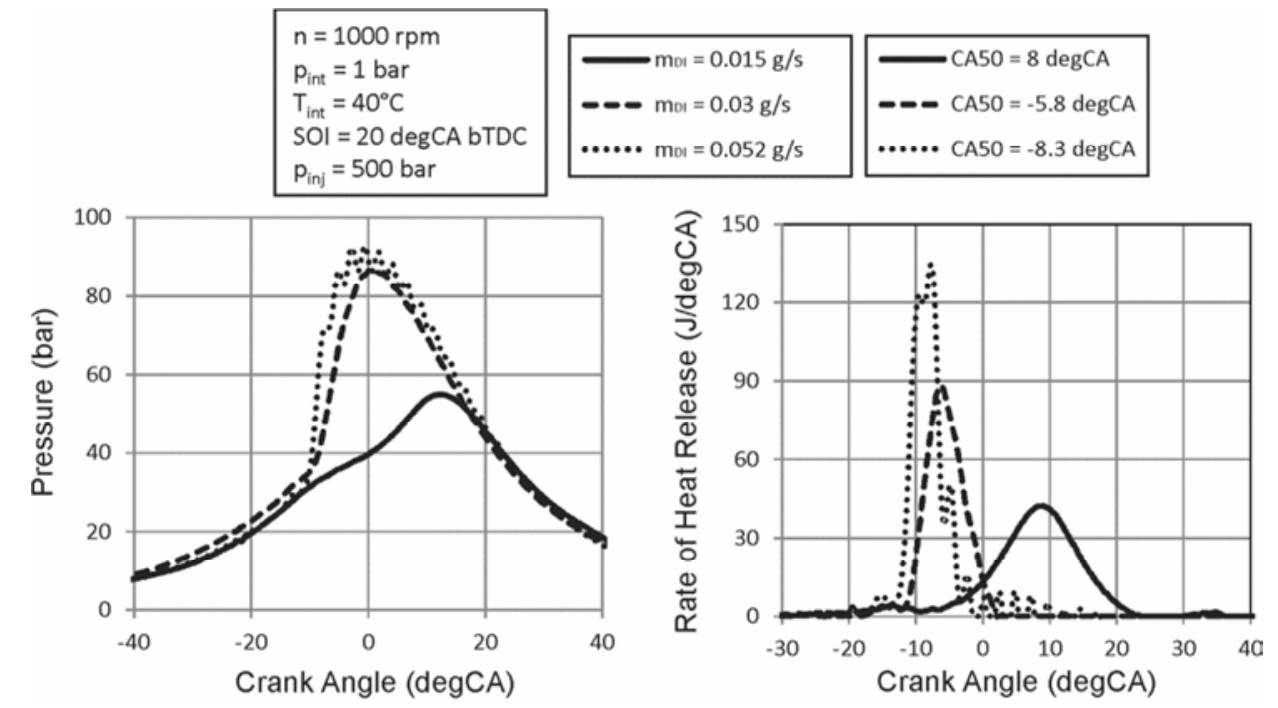

Fig. 6 In-cylinder pressure and rate of heat release for different diesel fuel masses

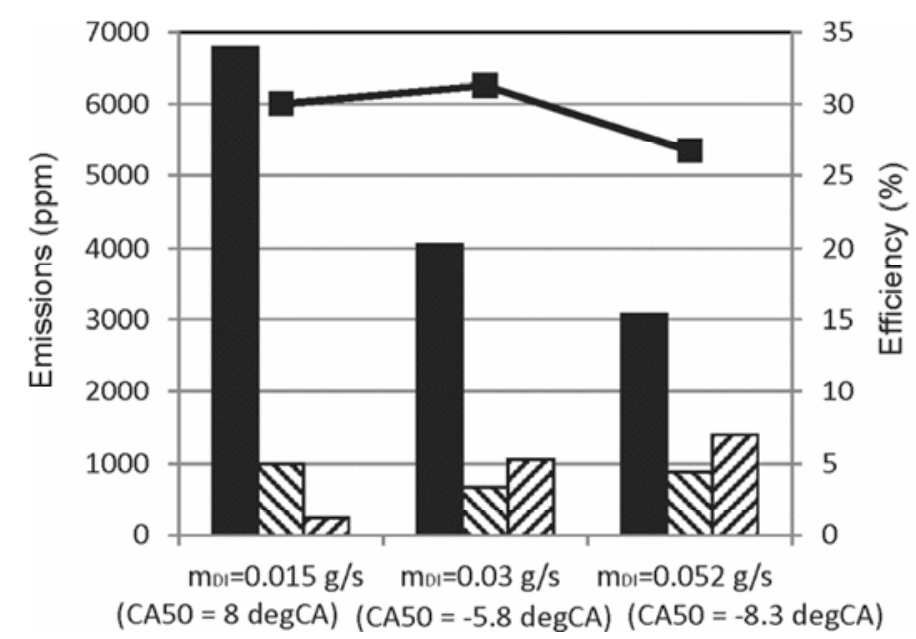

$$
\begin{aligned}
& \mathrm{n}=1000 \mathrm{rpm} \\
& \mathrm{p}_{\text {int }}=1 \mathrm{bar} \\
& \mathrm{T}_{\text {int }}=40^{\circ} \mathrm{C} \\
& \mathrm{SOI}=20 \mathrm{degCA} \text { bTDC } \\
& \mathrm{p}_{\text {inj }}=500 \mathrm{bar}
\end{aligned}
$$

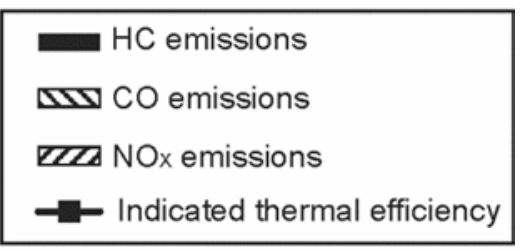

Fig. $7 \mathrm{HC}, \mathrm{CO}$ and $\mathrm{NO}_{\mathrm{X}}$ emissions and indicated thermal efficiency for different diesel fuel masses 
Generally, advanced combustion timing leads to an increase in the in-cylinder temperature and pressure which then leads to an increase in $\mathrm{NO}_{\mathrm{X}}$ emissions and a decrease in $\mathrm{HC}$ and $\mathrm{CO}$ emissions (Figure 7). Similarly to the effect of injection pressure and timing, the indicated thermal efficiency depends on the combustion phasing. Figure 7 shows that the initial increase in the diesel fuel mass led to an increase in the indicated thermal efficiency, while a further increase in the diesel mass led to a decrease in the indicated thermal efficiency due to overly advanced combustion phasing which led to increased heat losses.

In this section it has been shown how specific injection parameters influence combustion and hence performance and emissions of the conventional dual fuel engine. It is evident that in order to optimize injection and thus ignition settings and consequently combustion phasing and operating point efficiency, it is necessary to account for all three influencing parameters. While injection timing and Diesel fuel mass were found to have a profound effect on exhaust gas emissions as well as combustion phasing and intensity, the injection pressure was found to have only an effect on exhaust gas emissions, while the combustion phasing remained fairly constant as injection pressure was altered.

\subsection{Diesel fuel substitution ratio}

The effect of diesel fuel substitution at a constant load has been presented in $[12,13]$. As has been mentioned before, the introduction of CNG leads to longer ignition delay, which can lead to excessive mixing in the spray region, decrease in the in-cylinder temperature at the top dead center and eventually lead to incomplete combustion and a decrease in combustion and thermal efficiencies (Figure 8). Generally, as the methane quantity increases, both HC and CO emissions increase (Figure 9). A different trend was only observed at higher loads [13], where after an initial increase there is a decrease in $\mathrm{HC}$ emissions due to the more complete flame propagation as the $\mathrm{CNG}$ quantity increased and the premixed mixture excess air ratio decreased.

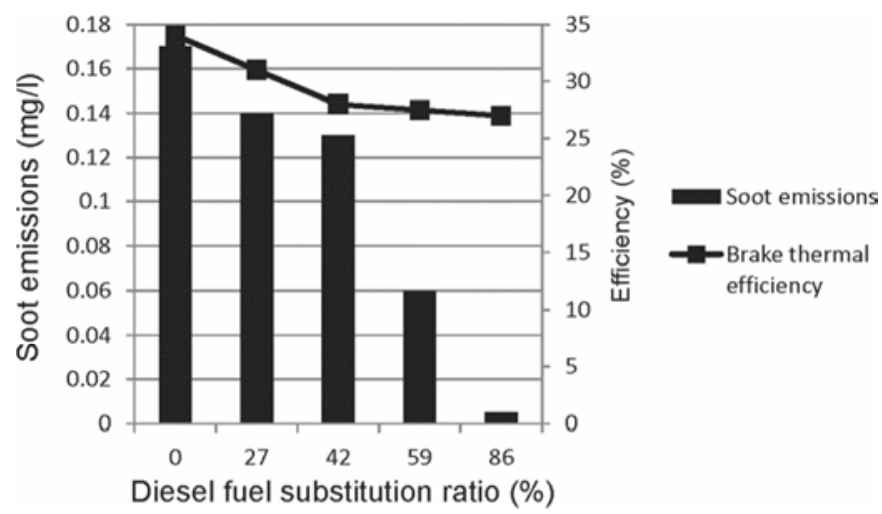

Fig. 8 Soot emissions and BTE vs. diesel fuel mass substitution ratio. Reproduced from [13]

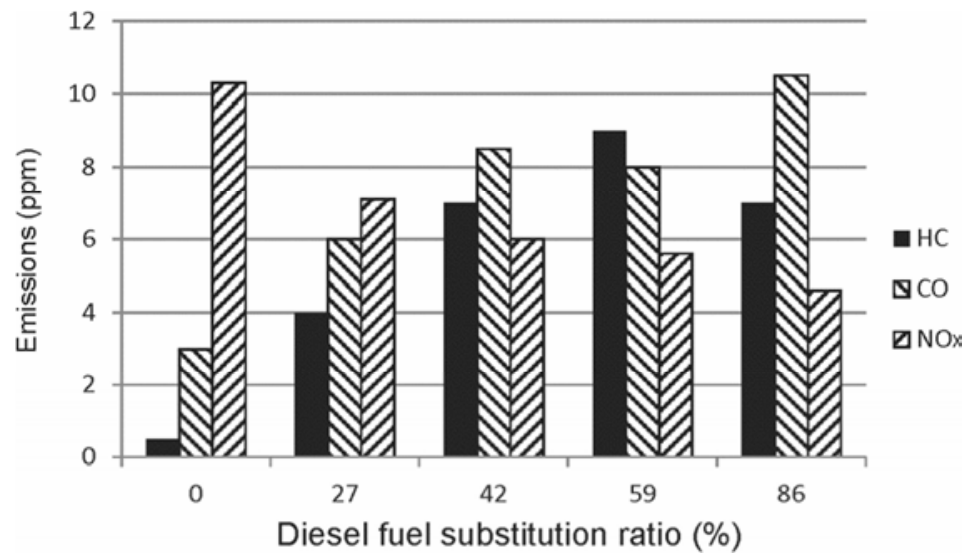

Fig. $9 \mathrm{HC}, \mathrm{CO}$ and $\mathrm{NO}_{\mathrm{x}}$ emissions at high load. Reproduced from Error! Reference source not found. 
A decrease in the excess air ratio results in an increase in the laminar flame velocity thus enabling faster and more complete flame propagation, which leads to an increase in the brake thermal efficiency (BTE) [13]. $\mathrm{NO}_{\mathrm{X}}$ emissions generally decrease as the methane quantity increases, which is due to the lower local temperature during combustion. It is important to stress that different trends might occur if the injection timing is changed as the methane quantity is increased. This is evident from [12], where in the dual fuel case a slight increase in $\mathrm{NO}_{\mathrm{X}}$ emissions at high load was observed. Soot emissions decrease sharply as the CNG quantity increases at all loads. In [13] it has been shown that the brake thermal efficiency decreased at all loads as the CNG quantity increased. On the other hand, in [12] it has been shown that the specific fuel consumption is lower in the dual fuel model (efficiency is higher) compared to the pure diesel case. This leads to a conclusion that the efficiency is not solely dependent on the fuel mixture but is influenced (as seen before) by the injection settings which have to be optimized for each $\mathrm{CNG} /$ diesel mixture ratio.

\subsection{Engine load and speed}

In the conventional dual fuel engine, load is usually increased through the increase in the CNG mass flow, while the diesel fuel mass flow is kept at the same rate. In Figures 10 and 11 it can be seen that as the load increases the $\mathrm{HC}$ emissions decrease, while the $\mathrm{NO}_{\mathrm{X}}$ emissions and the indicated thermal efficiency increase. This is a result of better flame propagation at higher loads that is due to a lower excess air ratio in the premixed CNG/air mixture. The lower excess air ratio increases the laminar flame speed thus increasing the incylinder temperature and decreasing the combustion duration.

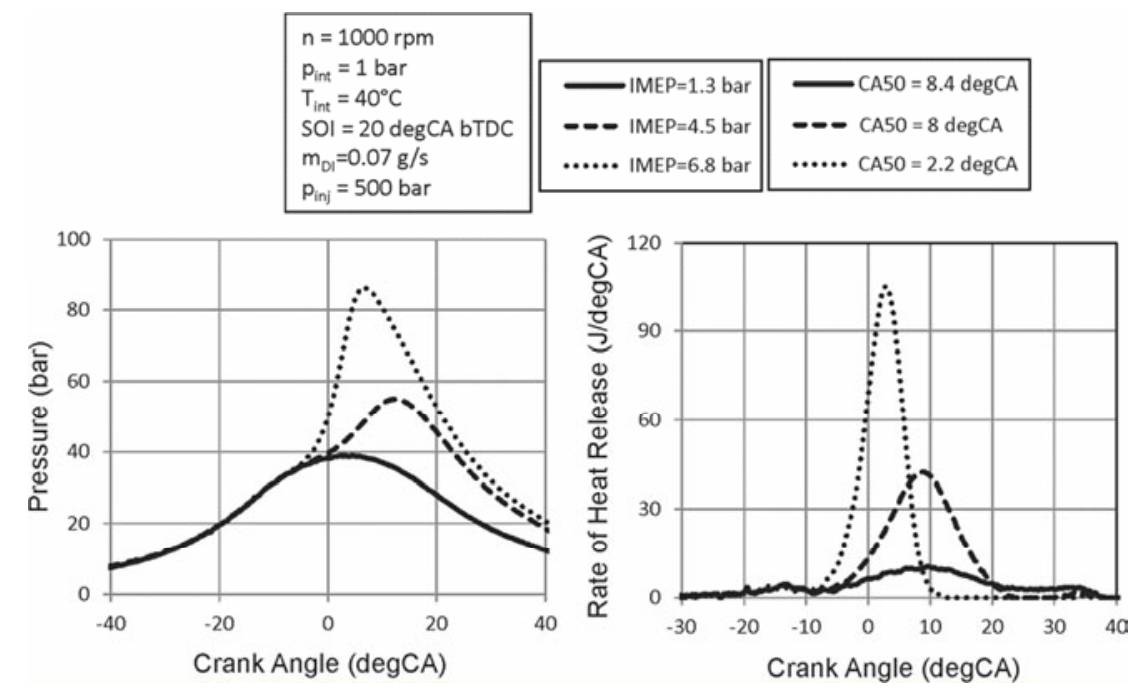

Fig. 10 In-cylinder pressure and rate of heat release at different load levels
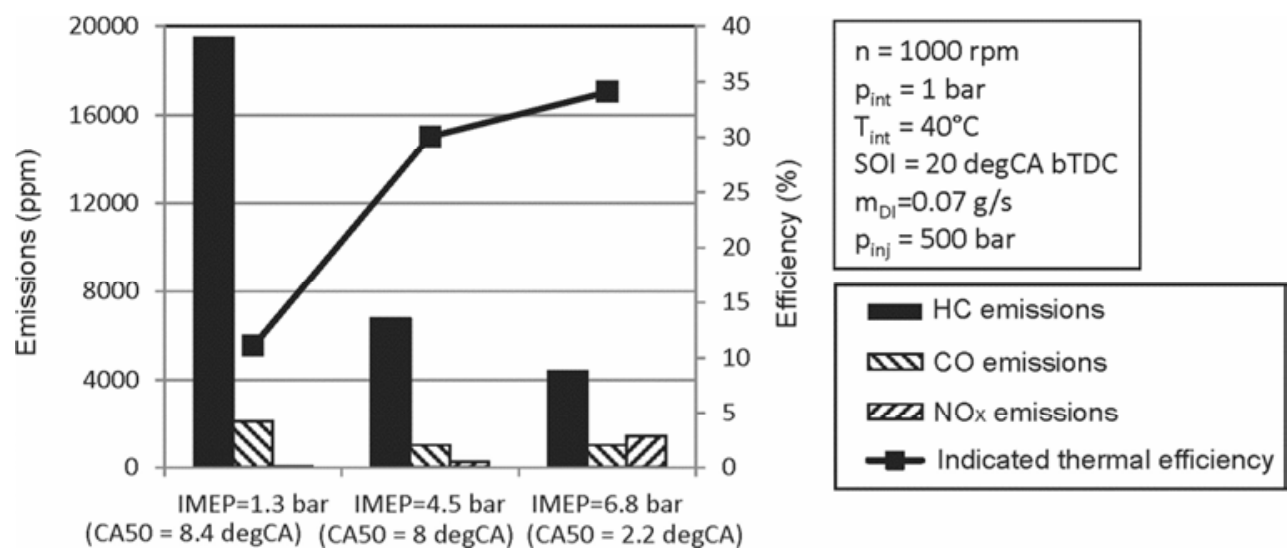

Fig. $11 \mathrm{HC}, \mathrm{CO}$ and $\mathrm{NO}_{\mathrm{X}}$ emissions and indicated thermal efficiency at different load levels 
By comparing the conventional dual fuel operation to the Diesel operation, it is evident that the conventional dual fuel engine suffers from low efficiency and extreme $\mathrm{HC}$ and $\mathrm{CO}$ emissions at low loads due to the inability to achieve the propagation of adequate flame through the too lean premixed mixture. On the other hand, satisfactory operation at a medium and high load can be achieved with the efficiency comparable to that of a Diesel engine. Moreover, soot emissions are considerably lower in the entire load range, while $\mathrm{NO}_{\mathrm{X}}$ emissions are lower at low and medium and even at high loads if the combustion process is optimized. Even though comparable or even higher efficiency can be achieved at high loads, $\mathrm{HC}$ emissions are higher in the entire load range compared to the Diesel engine. The maximum load in the conventional dual fuel engine is limited by the occurrence of knock [8]. In [20] it has been reported that if there is no preheating of the intake mixture, knock will occur at loads that are above the Diesel engine rated loads at the same engine speed.

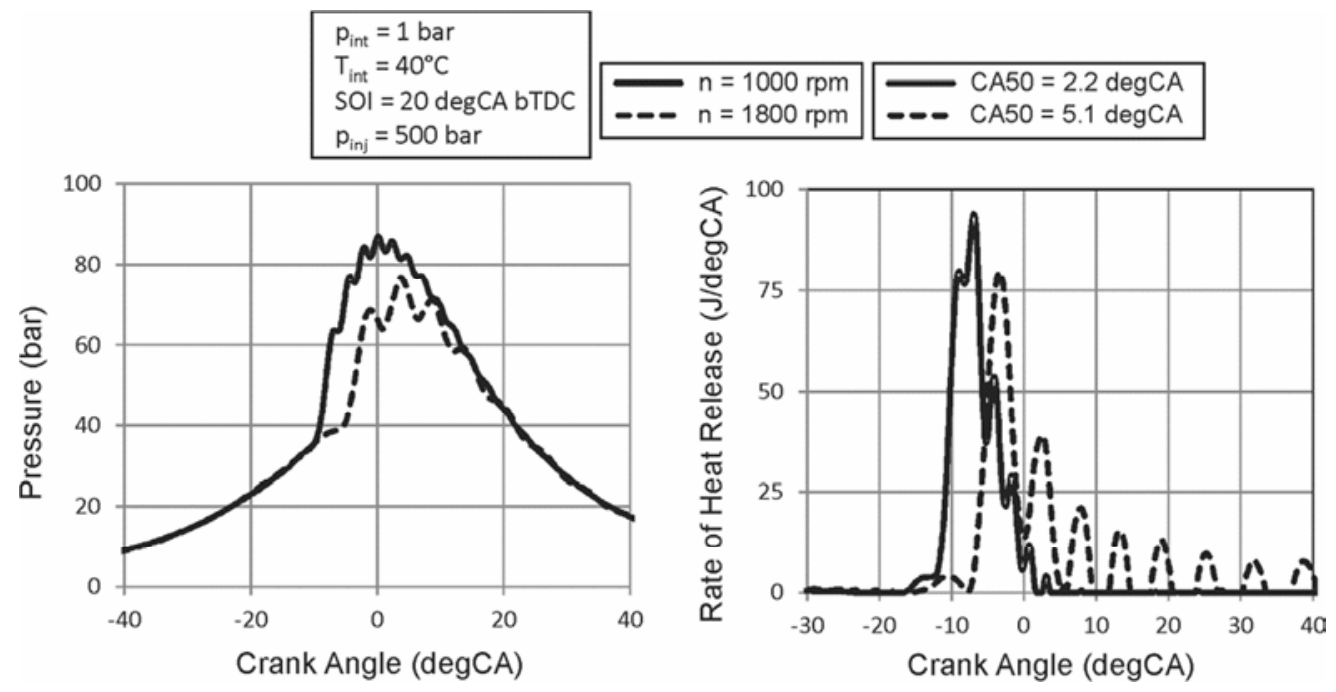

Fig. 12 In-cylinder pressure and rate of heat release at different engine speeds

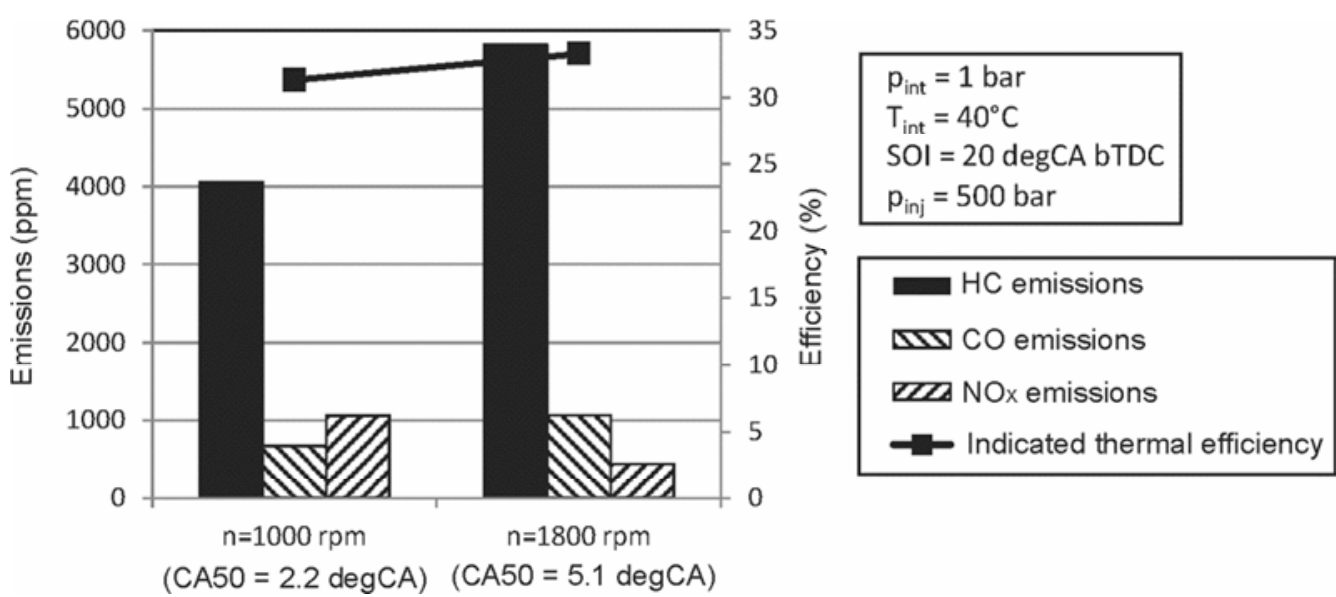

Fig. $13 \mathrm{HC}, \mathrm{CO}$ and $\mathrm{NO}_{\mathrm{X}}$ emissions and indicated thermal efficiency at different engine speeds

The previously discussed influences of injection parameters on combustion and engine performance are valid at all engine speeds. On the other hand, if one compares two engine speeds with the same operating parameters, the rate of heat release decreases and the combustion duration increases with the increase in the engine speed (Figure 13), which leads to a decrease in peak temperatures and $\mathrm{NO}_{\mathrm{X}}$ emissions and an increase in $\mathrm{HC}$ emissions (Figure 13). In the investigated engine, the increase in the engine speed led to an increase in the indicated thermal efficiency due to more optimal combustion phasing and decrease in heat losses. Besides on performance, the engine speed has a strong influence on pressure 
oscillations (waves) created in the cylinder during combustion. In Figure 12 it can be seen that at a higher engine speed a similar pressure rise rate expressed in $\mathrm{MPa} / \mathrm{deg}$ causes larger pressure oscillations. These oscillations lead to an increase in noise and they can also lead to damage of engine vital parts.

\subsection{Intake charge conditioning}

In [21], the authors studied the effect of different boost levels on the dual fuel engine performance and as expected the increase in boost level results in an increase in the dual fuel engine power output. However, as intake pressure and temperature increase, knock tendency increases as well.

The reviewed papers [21, 23] showed that the intake temperature increase leads to an increase in combustion efficiency. As the intake air temperature is increased, air mass inside the cylinder decreases which leads to a decrease in the premixed excess air ratio, which in combination with higher temperatures leads to more complete flame propagation. This leads to an increase in efficiency and $\mathrm{NO}_{\mathrm{X}}$ emissions and a decrease in $\mathrm{HC}$ and $\mathrm{CO}$ emissions. Generally, intake air preheating is useful at low and medium loads as it enhances flame propagation through the premixed mixture, while it should not be applied at higher loads because it increases the knock occurrence.

The effect of EGR has been studied in $[5,18,22,23]$. The application of hot EGR at low loads increases the intake mixture temperature and therefore promotes flame propagation through the premixed mixture which then increases combustion and the indicated thermal efficiency [5]. On the other hand, cold EGR gives the indicated thermal efficiency which is somewhat lower at high loads [18], but lowers the $\mathrm{NO}_{\mathrm{X}}$ emissions. This means that the choice between hot and cold EGR depends on specific demands [23].

\section{Conclusions}

In this paper, the effect of operating parameters (diesel fuel injection pressure, injection timing, diesel fuel mass, diesel fuel substitution ratio and intake charge conditioning) on the combustion process, performance and exhaust gas emissions from the dual fuel diesel/CNG engine have been described. Final conclusions about the influence of operating parameters on dual fuel combustion are:

- The influences of different injection settings (pressure, diesel fuel mass flow and start of injection timing) are interconnected. Optimized performance can only be obtained with adequate injection settings of all three parameters. Even though the increase in injection pressure generally leads to an increase in the indicated thermal efficiency, without adequate control of combustion phasing a decrease in the indicated thermal efficiency and an increase in $\mathrm{HC}$ and $\mathrm{CO}$ emissions can occur. The same approach must be taken when the injection timing setup and diesel fuel mass flow are defined. A too advanced setting of the injection timing can lead to fuel over-mixing and even misfires, while the setting of the injection too late can overly retard the combustion phasing and cause a sharp increase in $\mathrm{HC}$ emissions. The influence of the diesel fuel mass exhibits a linear trend; by increasing the diesel fuel mass, the premixed combustion phase is enhanced, which results in an increase in $\mathrm{NO}_{\mathrm{X}}$, on the one hand, and a reduction in $\mathrm{HC}$ and $\mathrm{CO}$ emissions, on the other hand. However, without adequate combustion phasing control the increase in the diesel fuel mass flow could lead to a decrease in the indicated thermal efficiency. 
- It has been found that injection pressure has a profound effect on exhaust gas emissions, while it has a minor effect on combustion phasing.

- On the other hand, the Diesel fuel mass and injection timing have been found to have a profound effect on both exhaust gas emissions and combustion phasing. Therefore, these two controlling parameters can be used to optimize a specific operating point in terms of indicated efficiency.

- Load increase is generally achieved through an increase in CNG amount. This leads to a decrease in the premixed mixture excess air ratio, which promotes flame propagation through the combustion chamber and increases the in-cylinder temperature. Hence, the increase in load leads to a decrease in $\mathrm{HC}$ emissions, while $\mathrm{NO}_{\mathrm{X}}$ emissions increase.

- Preheating of the intake air leads to an increase in the indicated thermal efficiency and a decrease in $\mathrm{HC}$ emissions at low and medium loads, while at high loads it increases the knock occurrence. Hot EGR leads to an increase in the indicated thermal efficiency at low loads, while cold EGR gives lower indicated thermal efficiency but decreases $\mathrm{NO}_{\mathrm{X}}$ emission at high loads.

\section{ACKNOWLEDGMENTS}

The experimental results have been obtained at the Combustion Analysis Laboratory of the University of California Berkeley through the research activities of Ivan Taritaš and Mislav Blažić. The authors would like to thank the entire staff of the Combustion Analysis Laboratory of the University of California Berkeley for all their help, especially Professor Robert Dibble for hosting Ivan Taritaš and Mislav Blažić and dr. David Vuilleumier and Miguel Sierra Aznar for all their help in conducting the research activities.

This study was performed within the FMENA project "Experimental Research, Optimization and Characterization of piston engine operation with DUal-Fuel COmbustion - DUFCOROC" IP-2014-09-1089 funded by the Croatian Science Foundation. This help is gratefully appreciated.

\section{REFERENCES}

[1] Korakianitis T., Namasivayam A.M., and Crookes R.J.: Natural-gas fueled spark-ignition (SI) and compression-ignition (CI) engine performance and emissions. Progress in Energy Combustion and Science Vol. 37, pp. 89-112, 2011. DOI: 10.1016/j.pecs.2010.04.002

[2] Yu Q., Cai M., Shi Y., Fan Z.: Optimization of the Energy Efficiency of a Piston Compressed Air Engine. Journal of Mechanical Engineering 60(2014)6, pp. 395-406, 2014.

[3] Barmaki R., Ilkhani M., Salehpour S.: Investigation of energy usage an emissions on plug-in and hybrid electric vehicle. Tehnički Vjesnik 23(3), 2016. DOI: 10.17559/TV-20140928112417

[4] Dahadwala M., Joshi S., Koehler E.W., and Franke M.: Investigation of Diesel and CNG Combustion in a Dual Fuel Regime and as an Enabler to Achieve RCCI Combustion. SAE Technical Paper 2014-01-1308, 2014.

[5] Serrano D., Bertrand L.: Exploring the Potential of Dual Fuel Diesel-CNG Combustion for Passenger Car Engine. Proceedings of the FISITA 2012 World Congress.

[6] Sahoo B.B., Sahoo N., Saha U.K.: Effects of engine parameters and type of gaseous fuel on the performance of dual-fuel gas diesel engines - A critical review. Renewable and Sustainable Energy Reviews Vol. 13, pp. 1151-1184, 2008. DOI: 10.1016/j.rser.2008.08.003

[7] Cho H.M., He B-Q.: Spark ignition natural gas engines - A review. Energy Conversion and Management Vol. 48, pp. 608-618, 2007. DOI: 10.1016/j.enconman.2006.05.023

[8] Konigsson F.: Advancing the limits of Dual Fuel Combustion. Licenciate thesis, Royal Institute of Technology Stockholm, 2012. 
[9] Mc Taggart-Cowan G., Mann K., Wu N., Munshi S.: An Efficient Direct-Injection of Natural Gas Engine for Heavy Duty Vehicles. SAE Technical Paper 2014-01-1332, 2014.

[10] Kozarac D., Taritas I., Vuilleumier D., Saxena S., Dibble R.W.: Experimental and numerical analysis of the performance and exhaust gas emissions of a biogas/n-heptane fueled HCCI engine, Energy Vol. 115, pp. 180-193, 2016. DOI: 10.1016/j.energy.2016.08.055

[11] http://www.targettrainingcentre.nl/news/special/

[12] Lounici M.S., Loubar K., Tarabet L., Balistrou M., Niculescu D.C., and Tazerout M.: Towards improvement of natural gas-diesel dual fuel mode: An experimental investigation on performance and exhaust emission. Energy Vol. 64, pp. 200-211, 2014. DOI: 10.1016/j.energy.2013.10.091

[13] Papagiannakis R.G., Rakopoulos C.D., Hountalas D.T., Rakopoulos D.C.: Emissions characteristics of high speed dual fuel, compression ignition engine operating in a wide range of natural gas/diesel fuel proportions. Fuel, Vol. 89, pp. 1397-1406, 2010. DOI: 10.1016/j.fuel.2009.11.001

[14] Sremec M., Taritas I., Sjeric M., Kozarac D.: Numerical Investigation of Injection Timing and Knock on Dual Fuel Engine. SEE SDEWES Conference, Piran, Slovenia, 2016.

[15] Shah S.S., Thipse A., Rairikar S.D., Kavthekar K.P., Marathe N.V. and Mandloi, P.: Literature Review and Simulation of Dual Fuel Diesel-CNG Engines. SAE Technical Paper SAE 2011-26-0001, 2011.

[16] Wei L., Geng P.: A review on natural gas/diesel dual fuel combustion emissions and performance. Fuel Processing Technology, Vol. 142, pp. 264-278, 2016. DOI: 10.1016/j.fuproc.2015.09.018

[17] Blažić M.: Testing and Performance Analysis of Dual Fuel Engine. Master's thesis, University of Zagreb, 2016.

[18] Daisho Y., Yaeo T., Koseki T., Saito T., Kihara R., Quiros E.N.: Combustion and Exhaust Emissions in a Direct-Injection Diesel Engine Dual-Fueled with Natural Gas. SAE Technical Paper SAE 950465, 1995.

[19] Yang Y., Dec J., Dronniou N., and Cannella W.: Boosted HCCI Combustion Using Low-Octane Gasoline with Fully Premixed and Partially Stratified Charges. SAE Int. J. Engines, Vol. 5(3), pp. 1075-1088, 2012. DOI: $10.4271 / 2012-01-1120$

[20] Wannatong K., Akarapanyavit N., Siengsanorh S., Chanchaona S.: Combustion and knock Characteristics of Natural Gas Diesel Dual Fuel Engine. SAE Technical Paper 2007-01-2047, 2007.

[21] Gharehghani A., Mirsalim S.M., Jazayeri S.A.: Numerical and Experimental Investigation of Combustion and Knock in a Dual Fuel Gas/Diesel Compression Ignition Engine. Journal of Combustion, Vol. 2012, 2012.

[22] Papagiannakis R.G.: Study of air inlet preheating and EGR impacts for improving the operation of compression ignition engine running under dual fuel mode. Energy Conversion and Management, Vol. 68, pp. 40-53, 2013. DOI: 10.1016/j.enconman.2012.12.019

[23] Selim M.Y.E.: Effect of exhaust gas recirculation on some combustion characteristics of dual fuel engine. Energy Conversion and Management Vol. 44 707-721, 2003. DOI: 10.1016/S0196-8904(02)00083-3

Submitted: $\quad 20.7 .2016$.

Accepted: $\quad 25.1 .2017$
Ivan Taritaš, mag. ing. mech. ivan.taritas@fsb.hr Mario Sremec, mag. ing. mech. mario.sremec@fsb.hr Assis. Prof. dr. sc. Darko Kozarac darko.kozarac@fsb.hr Mislav Blažić mislav.blazic@fsb.hr Prof. dr. sc. Zoran Lulić zoran.lulic@fsb.hr University of Zagreb, Faculty of Mechanical Engineering and Naval Architecture

Ivana Lučića 5, 1002, Zagreb, Croatia 